\title{
Turismo, escuela e interculturalidad
}

\author{
Tourism, school and interculturality \\ Turismo, escola e interculturalidade \\ Fanny Monserrate Tubay Zambrano \\ Universidad de Cuenca, Ecuador \\ Universidad Nacional de Educación a Distancia UNED, \\ España \\ fannytubay@hotmail.com
}
DOI: https://doi.org/10.18472/cvt.19n1.2019.1398 Redalyc: http://www.redalyc.org/articulo.oa?
$\mathrm{id}=115459473013$

Recepción: 27 Enero 2017

Aprobación: 10 Octubre 2018

\section{Resumen:}

Este trabajo expone experiencias de guías turísticos rurales y estudiantes de la zona que interactúan en el Refugio de Vida Silvestre Marino-Costero de Pacoche (RVSMC) en Manabí - Ecuador. La metodología está basada en herramientas etnográficas, observación participante y entrevistas aplicadas al trabajo de campo. El objetivo es replantear el turismo desde el enfoque intercultural, originado desde la óptica de sus actores sociales, valorándolo como una oportunidad de desarrollo cultural y económico, pero a la vez cuestionándolo a partir de las teorías clásicas de la antropología, como una actividad cosificadora y poco coherente con las ideas que propone. Del encuentro de esas teorías y realidades locales, se plantea un enfoque desde las perspectivas etic y emic orientadas al ámbito intercultural. La interacción generada muestra una realidad no delimitada, que escucha, observa y extrae sus propias conclusiones en su forma de concebir la idea del turismo y su contribución a la interculturalidad.

Palabras Clave: Interculturalidad, Guías, Educación, Cultura, Turismo.

\section{Resumo:}

Este artigo descreve experiências de guias turísticos rurais e estudantes locais que interagem no Wildlife Refuge Pacoche Marinha e Costeira (RVSMC) em Manabi - Equador. A metodologia é baseada em ferramentas etnográficas, observação participante e entrevistas aplicadas ao trabalho de campo. O objetivo é repensar o turismo a partir da abordagem intercultural, originado a partir da perspectiva de seus atores sociais, valorizando-o como uma oportunidade para o desenvolvimento cultural e econômico, mas ao mesmo tempo questionando, a partir das teorias clássicas da antropologia, como uma atividade de reificação e pouco coerente com as ideias que propõe a partir do encontro dessas teorias e realidades locais. Propõe-se uma abordagem a partir das perspectivas éticas e êmicas orientadas para o campo intercultural. A interação gerada mostra uma realidade ilimitada, que escuta, observa e tira suas próprias conclusões, na maneira como concebe a ideia de turismo e sua contribuição para a interculturalidade.

PalaVras-CHAVE: Interculturalidade, Guias, Educação, Cultura, Turismo.

\section{Abstract:}

This paper exposes experiences of local tourist guides and students from the area who interact in the Pacoche Marine-Coastal Wildlife Refuge (RVSMC) in Manabí - Ecuador. The methodology is based on ethnographic tools, participant observation and interviews applied to the field work. The objective is to rethink tourism from the intercultural perspective, originated from the perspective of its social actors, valuing it as an opportunity for cultural and economic development but at the same time questioning it from the classical theories of anthropology as a reification activity and little consistent with the ideas that it proposes. From the encounter of these theories and local realities an approach is proposed from the etic and emic perspectives oriented to the intercultural field. The interaction generated shows an unlimited reality, which listens, observes and draws its own conclusions in the way it conceives the idea of tourism and its contribution to interculturality.

KEYWORDs: Interculturality, Guides, Education, Culture, Tourism. 


\section{INTRODUCCIÓN}

El trabajo que emerge a partir de la realización del $\operatorname{TFM}^{[1]}$ en el máster en educación intercultural con la UNED Universidad Nacional a Distancia en España, durante el período 2013-2015, parte de una concepción social de repensar el turismo desde la perspectiva intercultural, como un hecho que se da por sentado y cuyo argumento defiende a la actividad, como eje de desarrollo sostenible en cualquiera de los ámbitos que se presente.

Si bien, a decir por los testimonios de las personas de la comunidad, la convivencia, el respeto, el amor por la naturaleza y la solidaridad, se exponen como elementos fundamentales del turismo; en la recolección de datos, estos, no son lo suficientemente coherentes ni menos coinciden con las teorías clásicas, en las que se observa el turismo como una actividad desigual, estereotipada y cargada de prejuicios, que en este caso se reproducen horizontalmente. Entendiéndose que más allá de ser un modelo de trabajo para las comunidades, esto ha ocasionado que se lo mire como algo prístino, propio del mercado folclorizador capitalista.

Desde el lado más paternalista, la investigación explora el mundo de los guías, en el ámbito de su trabajo en el "Sendero del Mono", resaltando un conocimiento empírico, válido desde su propia cosmovisión, alimentado a partir de experiencias de vida y expresado a través de una dinámica construida diariamente desde la interrelación con otros actores sociales.

Otro de los enfoques comprende la interacción educativa-comunitaria, reflejada en la relación de guías nativos de turismo con estudiantes del 3er año de bachillerato de la especialidad de Turismo del Colegio San Lorenzo en el Cantón Manta, armonizando el conocimiento universal con el empírico, en un entorno natural que traspasa el salón de clases y lo traslada al área natural, visibilizando cómo se promueven las sesiones escolares, la participación, la orientación del contenido académico, resaltando quienes son los facilitadores de ese aprendizaje, cómo se percibe esta modalidad y cómo se valora el aporte de los guías en el proceso de formación de los estudiantes, y la forma como todo este universo de ideas entrelazadas contribuye de algún modo a ayudar a encontrar pistas para captar el enfoque intercultural en ese espacio de aprendizaje.

\section{METODOLOGÍA}

El tipo de investigación que se aplica en la investigación, es de campo basada en la etnografía, aplicando metodológicas de observación acción participante y entrevistas.

La observación participante, se llevó a cabo en diferentes contextos de la Parroquia San Lorenzo, ubicada en la Provincia de Manabí - Ecuador: el Colegio Técnico San Lorenzo, el Área Protegida de Pacoche y sitios de influencia turística y comunitaria como son los casos de restaurantes y hogares que permitieron realizar el acercamiento voluntariamente, durante el año 2015.

Las entrevistas se dirigieron a los guías nativos del Área Protegida, se contó con la colaboración de seis de ellos, estas estuvieron orientadas en promover el diálogo abierto, en conocer experiencias motivaciones y necesidades conjugadas entre el turismo y el valor de la educación local. En otro ámbito las entrevistas realizadas a estudiantes se encuadraron en evaluar un modelo educativo que extrapola el aula hasta un sitio natural, propio de su entorno local. Y finalmente las entrevistas a los actores socio comunitarios se encausaron en las tradiciones y saberes de la comunidad, patrimonio inmaterial, apreciándolas desde su influencia en la escuela, el turismo y el entorno.

Por cuestiones de respeto hacia los entrevistados, se muestran los aportes de cada uno de ellos a través de un código alfa numérico, en el contenido de este trabajo,

G para los guías y M para el maestro del colegio: G1- G2- G3- G4- G5- G6- M1.

M, para el maestro: M1.

Y P, para los profesionales colaboradores: P1- P2-P3- 
Se desarrolló también una metodología de tipo documental, en la que se analizó la LOEI, la Constitución de la República del Ecuador 2008 y el MOSEIB (Modelo del Sistema de Educación Intercultural Bilingüe), en función de las teorías y los resultados de observación y entrevistas.

\section{RESULTADOS}

\subsection{Turismo y educación intercultural}

Las relaciones que se establecen en esta actividad dinámica, denominada Turismo, considerada como la tercera fuente de ingresos no petroleros en Ecuador, y cuya meta es, sin embargo, convertirlo en la primera fuente de dichos ingresos, según la Agencia Andes Mintur ${ }^{[2]}$ (2015) tiene un nexo estrecho con la interculturalidad que en ocasiones se asume como una correlación natural, que le da valor agregado a la gestión turística.

En ese mismo sentido, consultando con profesionales en ese ámbito en Manabí ${ }^{[3]}$ sobre esta aparente relación, se han obtenido respuestas que entretejen al turismo con la interculturalidad, pero que también contraponen las teorías clásicas de la antropología con los argumentos del turismo, si fijamos la mirada hacia el visitante y el visitado.

Con gran certeza, varios profesionales en turismo consultados durante este trabajo, acentúan por un lado que, existe un "nexo indiscutible entre turismo e interculturalidad" (P1), bien sea

porque a la cultura se la relaciona con el conocimiento de otras dimensiones espaciales y temporales (tradiciones, costumbres, idiomas, música, arte o gastronomía) asociadas al turismo, o porque se trata de una actividad que mezcla múltiples elementos que sirven de atractivos o complementos turísticos, lo que hace que automáticamente se le asigne el sujeto "intercultural" a esta actividad (P2).

Una catedrática del turismo en una universidad local de Manabí, en una entrevista informal, sostiene que la relación es total, puesto que aun cuando se defiende la autenticidad y la conservación de la identidad natural y autóctona, la interculturalidad e inculturación son efectos colaterales. Otro funcionario afirma:

sí por supuesto, por donde se lo mire, en el mercado interno lo que ofrecemos son nuestras costumbres (cultura) que son muchas. [...], que nuestros productos turísticos locales y mundiales nacen de los recursos naturales y culturales, desde ese momento ya estamos hablando de cultura y su diversificación en el país, somos un país multicultural (P3).

Acorde a estas afirmaciones se puede percibir que el turismo y la interculturalidad tienen una relación subjetiva, que se da por sentada o que va de la mano desde el discurso teórico. Valdría entonces analizar cómo la educación y los conceptos interculturales, así como los años de investigación de especialistas en esta área, coinciden o no, con los preceptos que el turismo sostiene, ya sea por prácticas tradicionales o por qué sencillamente la humanización del turismo no se visibiliza desde la punta del iceberg.

\subsection{Repensando y cuestionando el turismo}

En el intento de repensar el turismo, desde la perspectiva de profesionales y de cómo en cierta forma se aborda la interculturalidad en determinados sectores comunitarios con influencia capitalista, se puede inferir que el término se lo extrae de la "inter" "cultura", mezclar las culturas, observarlas, establecer criterios, hacer ferias y eventos de carácter cultural. Esto en el caso de los turistas que visitan un determinado lugar; pero, ¿qué ocurre entonces con las personas locales?, ¿en qué medida esta relación beneficiosa se evalúa localmente? ¿Estamos cayendo en el esencialismo del turismo intencionalmente o en realidad es una práctica totalmente ingenua? 
¿Por qué nos cuesta evolucionar hacia un pensamiento más dinámico en el que la cultura deja de ser algo inmóvil, legítimo y antiguo?

Zapata (2013, p. 2) al hacer mención de sus percepciones del turismo y el etnoturismo desde su mirada crítica, señala:

Los riesgos de este fenómeno general, comprobables en nuestro terruño, son previsibles: naturalización de la desigualdad económica (cuando se asume que la pobreza, el aislamiento y la falta de comodidades son parte de ese mundo ancestral), fetichización cultural, exotización, autoexotización y cosificación, no remontable por la interacción y el "hacerse amigo ${ }^{[4]}$.

En virtud de lo mencionado, se ha intentado recoger algunos conceptos derivados de las bases conceptuales de la Interculturalidad y del modelo de educación que propone el turismo en el colegio San Lorenzo, cómo el turismo puede o no ayudar a valorar la diversidad y propiciar espacios de convivencia basados en el respeto de la otredad, no cómo aquel "otro exótico" (KALINSKY; PÉREZ, 1993, p. 52) sino como ese otro, que está presente en toda la diversidad del ser humano. La intención sin embargo, no es cuestionarlo, para darle una solución, sino propiciar una reflexión que nos ayude a encontrar el camino y el sentido a la interculturalidad como lo propone el PNBV ${ }^{[5]}$, como una práctica constante que impacte positivamente en la actividad turística.

Partiendo de la conceptualización que se da al turismo desde la $\mathrm{OMT}^{[6]}$, definiéndolo como un fenómeno social, cultural y económico relacionado con el movimiento de las personas a lugares que se encuentran fuera de su lugar de residencia habitual por motivos personales o de negocios/profesionales.

La cultura, más allá de la economía, el desarrollo sostenible o la interacción social, juega un papel condicionante en el sector turístico, convirtiéndola en una definición cargada de significados culturales y de una diversidad que a veces entona y en otras desentona con las definiciones interculturales, muchas de ellas asociadas por los expertos en turismo como una relación natural.

En su conferencia, en el Seminario sobre Cultura y Desarrollo (WASHINGTON, 2005), Canclini, asienta que la cultura no es vista ahora como un bien suntuario, una actividad para los viernes a la noche o los domingos de lluvia, en la cual los gobiernos tienen que gastar, sino un recurso para atraer inversiones, generar crecimiento económico y empleos.

Esos fundamentos nos llevan a pensar en una cultura con vida propia, capaz de transformarse y responder a las necesidades de las personas. Por otro lado, nos ayuda a rescatar el término "cultura" de los límites simbólicos, en el que se lo ha encasillado como algo inflexible y caricaturesco, analizado desde un punto turístico.

Ruhly (1976) citada por Malik (2003) en "Desarrollo de competencias interculturales en orientación", compara la cultura con un iceberg, en el sentido de que sólo una pequeña parte de ella puede ser percibida, mientras que la parte más importante se oculta a la vista. Probablemente sea esta, una metáfora que se ajusta a este tipo de realidad, llamando cultura a lo que tradicional y visualmente se encuentra a nuestro alcance. En términos prácticos se puede llegar a llamar cultura a las celebraciones y fiestas religiosas, la gastronomía o la vestimenta típica; sin llegar a reconocer las profundas connotaciones invisibles, que son las que le dan sentido a las formas de vida de los pueblos en el mundo y que nos hacen diferir del significado de cultura.

La interculturalidad intenta romper con la historia hegemónica de una cultura dominante y otras subordinadas y, de esa manera, reforzar las identidades tradicionalmente excluidas para construir, tanto en la vida cotidiana como en las instituciones sociales, un con-vivir de respeto y legitimidad entre todos los grupos de la sociedad (WALSH, 2009, p. 41).

En este ámbito, la atención a la diversidad cultural de los habitantes de los pueblos del mundo, en particular de San Lorenzo, lugar en el que se desarrolla este trabajo de investigación, no sólo responde a términos éticos o de respeto, sino también a la valoración de un aprendizaje sostenible útil en el diario vivir, aplicable y básico en el contexto educativo, teniendo en cuenta que, de ahí parten las atenciones a la familia, la sociedad, la cultura, 
como ámbitos desde donde lastimosamente germinan, aceleradamente las semillas de discriminación, abusos de poder y desigualdad.

"La educación intercultural propone una práctica educativa que sitúe las diferencias culturales de individuos y grupos como foco de la reflexión y la indagación en educación” (AGUADO, 2005, p. 43) expresando un reclamo hacia un modelo de educación de calidad y socialmente justa, en la que se valore la identidad cultural y el conocimiento local como parte de un curricular escolar de constante reflexión y lucha por establecer relaciones horizontales entre guías nativos, estudiantes, entes comunitarios y actores sociales externos.

\subsection{La experiencia de ser guia en Pacoche}

"Para la mayoría de los académicos, la relación entre el colonialismo y el turismo se resume poco más que en una observación casual o anecdótica, a menudo en los turistas mismos” (SALAZAR, 2006, p. 103). Afirmación que no sólo engrosa asimétricamente los pilares básicos de las relaciones humanas dentro de la actividad, sino que contempla el turismo desde la lupa del turista, limitando la voz de quienes hacen turismo y debiendo satisfacer las necesidades mercantilizadas de sus visitantes.

Sin duda, utópicamente la interculturalidad, el turismo y la escuela podrían encontrar medios de acercamiento que beneficien y trabajen conjuntamente, sin restar privilegios a unos y otros, las relaciones visitante-visitado podrían propiciar espacios de encuentros basados en la diversidad y su paridad.

Sin embargo, este discurso es expuesto por los guías nativos de San Lorenzo, desde su propia visión, una visión que se basa en la experiencia de ser lo que son, sin cuestionamientos.

Así, por ejemplo, el mayor de los guías nos invita a acompañarlo en su recorrido de trabajo en un día sábado, inicia con el primer grupo de turistas que visita el área protegida. Al presentarse antes los visitantes, se describe a sí mismo, como un hombre oriundo de la zona, con 67 años de edad, continúa comentando que, a los 17 años empezó a utilizar zapatos y que no asistió a la escuela, todo lo que sabe lo aprendió de la vida, de las enseñanzas de sus padres, de las largas jornadas de trabajo en agricultura y pesca.

Textualmente señala: "he recorrido cada rincón de la zona con mi abuelo, mi padre y hoy con mis hijos y nietos" (G1) ${ }^{[7]}$, haciendo referencia a que otro de los guías es su hijo.

Su labor, más que un trabajo, la describe como una conversación entre hombre-naturaleza, cada especie de flora y fauna tiene un significado para él y tiene una función especial en el bosque y en el mundo, "una planta sin necesidad de hablar puede decir cuál es su territorio", señala G1.

A lo largo del recorrido hace mención de todo aquello que tiene significancia según su punto de vista: el ritual de los monos aulladores, las formas de relacionarse, aparearse, explicando la forma como los monos dan a conocer quién es el más fuerte de la manada, el ciclo de reproducción de las hembras, el pelaje grueso y obscuro de los machos o el rostro y pelaje fino de las hembras, las características del género, las formas de alimentación, los ciclos de vida, son sólo algunas de las valiosas representaciones que genera su intervención hacia los turistas.

Durante esta jornada de observación participante, se hace evidente la interacción permanente, en ocasiones, él puede llegar a ser un consejero o una fuente de información válida y alternativa a lo que ya conocen previamente sus turistas. En algunos transectos, se detiene para hablar de los mitos del campo, de las plantas y árboles que han adquirido tal o cual forma por haber sido cortadas en luna llena o en fechas sagradas como la semana santa; para él el bosque es la representación de un laboratorio natural, del que conoce las recetas y dosis necesarias para cada enfermedad, desde soluciones para el estrés y migraña, hasta plantas y remedios para mitigar los efectos del cáncer, resalta además, el testimonio de vida que han dado las personas que se han curado con estas medicinas que provee el bosque. 
Sus habilidades narrativas demuestran experiencia de trabajo con grupos: voz, información, énfasis, tono, equilibrio emocional, el afán de no juzgar ni lo urbano ni lo rural como malo o bueno, sino como diferente. Su lenguaje autóctono, acompañado de palabras y frases típicas de la oralidad Manabita (machacar ${ }^{[8]} /$ enderezar el espinazo ${ }^{[9]}$, hacen que sea un personaje único y demandado dentro del bosque como guía.

Su trabajo se centra también en despertar los sentidos de sus visitantes (el olfato, la visión, audición y el tacto). Facilita un aprendizaje sencillo mezclado con conocimientos de geografía local y nacional. Con la etnografía, cuando habla de las formas de vida de los habitantes de su comunidad en diferentes épocas, los significados que tiene cada aspecto, que en ocasiones no resulta común para los demás, o de zoología cuando explica en detalle los ciclos de vida de cada especie animal que rodea el área, o de medicina natural, cuando con sus consejos invita a los turistas a volcarse por un estilo de vida ecológico.

Su guianza, es capaz de transmitir una serie de emociones que se contrastan con el entorno real que bordea la zona, las tradiciones, los saberes y trabajos ancestrales, los rituales, pueden ser contados desde otra perspectiva cuando el valor agregado es el reconocimiento de lo propio como una riqueza universal, capaz de inferir positivamente, no sólo en quien recepta el conocimiento sino también en quien lo cuenta.

\subsection{Inicios}

El común denominador de los guías nativos de Pacoche, es que todos tuvieron sus inicios a partir de la socialización del proyecto del área protegida que impulsaban el MAE ${ }^{[10]}$ y el GAD ${ }^{[11]}$ Municipal del Cantón Manta, ninguno de ellos estuvo vinculado previamente con el turismo. La convocatoria a un curso de guías naturalistas marcó el inició de este oficio; la formación en el curso duró un año, entre el período 2007 y 2008, como se expresa en el PMRVSMC ${ }^{[12]}$ de Pacoche, en el 2008 concluyó la capacitación de 44 guías nativos de la comunidad, y estuvo a cargo de profesionales expertos en ramas afines a lo que se puede observar en el bosque. "Cuando finalizó el curso se abrieron los senderos dentro del área y se colocaron las casetas informativas donde esperamos cada día a los turistas” (G2) ${ }^{[13]}$.

Lo que sí difiere en gran medida, entre ellos es la actividad previa que ejercían en la comunidad a través de oficios y trabajos tradicionales como la pesca, la agricultura o la albañilería. "Antes de ser guía era pescador (peón - que significa ser asistente en la embarcación donde se pesca) yo no era el dueño de la lancha, mis abuelos fueron pescadores y albañiles" (G5) ${ }^{[14]}$.

Difieren también las razones que los motivaron para dejar sus oficios y dedicarse a una actividad desconocida, lo cual significó un reto en sus vidas cuestionado por sus familiares y amigos, "me gusta la naturaleza y por eso decidí ser guía, durante el curso recibíamos asignaturas en aulas de clases y a veces al aire libre dentro del área protegida, cuando finalizamos nos dieron la licencia de guías emitida por el Ministerio de Ambiente del Ecuador" (G6) ${ }^{[15]}$

"No conocía nada de esto antes de ser guía, todo lo tuve que aprender, esta zona donde estamos ahora se la conocía como la montaña, antes no pasaba la carretera por aquí [ $\mathrm{Al}$ referirse a la carretera que une San Lorenzo con la ciudad de Manta]. Antes no éramos conscientes de la oportunidad que representa el turismo para nosotros" $(\mathrm{G} 7)^{[16]}$.

Esta misma persona, comenta que el requisito para ser guías, era ser nativo de la zona rural adyacente a San Lorenzo, sus comunas, recintos y puntos; haber culminado el colegio no era un requisito obligatorio.

\subsection{Barreras}

Las limitaciones y obstáculos encontrados por estas personas, han sido una cuestión repercusiva en sus inicios, no sólo porque han tenido que enfrentarse al rechazo de la comunidad, o a la crítica de sus familias por 
abandonar sus oficios tradicionales, sino también por los constantes cuestionamientos que les hacían los visitantes, cuando los escuchaban hablar o determinaban a través de prejuicios, una relación de desigualdad entre ambas partes. "No importa como se llame a las diferentes partes involucradas, la relación entre los turistas y personas que habitan los destinos es marcadamente asimétrica" (SALAZAR, 2006, p. 106)

"Al inicio en esta profesión, los turistas no se acostumbraban a que personas nativas fueran guías, nos insultaban y decían cosas feas" (G2) ${ }^{[17]}$. Con el paso del tiempo esta situación ha ido cambiando y ellos a través del trabajo profesional que realizan han logrado eliminar en cierta medida, esos rezagos que son repetitivos en las sociedades urbanas, cuando de lo rural se trata. En adelante, han demostrado ser los actores principales de su entorno laboral.

Otra de las desavenencias por las que pasaron ocurrió cuando conformaron la asociación de guías nativos, y decidieron cobrar el valor de dos dólares por cada visitante que ingrese al área protegida. Muchos de los turistas pensaban que los estaban estafando, puesto que existe hasta la actualidad, una resolución ministerial en la que se decreta la gratuidad de las tarifas de entrada a las áreas protegidas en el Ecuador Proyecto Sostenibilidad Financiera del Sistema Nacional de Áreas Protegidas 00073902. (MINISTERIO DE AMBIENTE DEL ECUADOR, 2012).

$\mathrm{Al}$ ser su centro de trabajo un espacio protegido por el estado, solicitaron al Ministerio de Ambiente del Ecuador, por sus siglas MAE, el respectivo permiso para cobrar esa tasa, argumentando la accesibilidad al trabajo comunitario como un impulso a los pueblos rurales. La resolución fue dada a favor de los guías y desde ese momento, han podido realizar sus labores sin mayor inconveniente legal.

Y la barrera más significativa, según uno de los guías en constante autoformación, es el no hablar inglés; esto en ocasiones hace que se bloquee el proceso comunicativo en el plano formal, en otros casos la necesidad de comunicación hace que se desarrollen otras habilidades como el lenguaje interpretativo a través de señas.

\subsection{Beneficios y oportunidades}

Esta actividad, les ha cambiado la forma de ver la vida y de valorar el trabajo. Él, señala las diferencias entre el trabajo que desempeñaba antes de dedicarse a esta profesión y el que tiene actualmente, señala, "cuando era pescador utilizaba la fuerza de su cuerpo para generar ingresos, pasaba largas jornadas expuesto al sol, la lluvia o el frio de las faenas nocturnas, era un trabajo muy difícil" $(\mathrm{G} 2)^{[18]}$; desde que se inició en la guianza, afirma que su trabajo depende de su intelecto y de aquello que conoce naturalmente, trabajar se ha convertido para él, en una recreación sin presiones, disfruta el contacto con la naturaleza y caminar por los senderos, lo cual considera un privilegio.

"Cada vez más los turistas están buscando vacaciones que respondan a su deseo de aprender, de nostalgia, de autenticidad” (BOISSEVAIN, 2005, p. 219). En determinadas ocasiones los guías señalan que, el turista viene con un conocimiento previo del lugar o bien comparan lo que hay aquí, con lo que hay en su lugar de origen y eso además de generar más conocimiento, les produce curiosidad por conocer en que se parecen y en qué se diferencian,

hace unos meses vinieron unas turistas argentinas y cuando le explicaba sobre la plante del Mate, estaban sorprendidas del uso que le damos e inclusive la forma diferente que tiene la planta que crece en Argentina [...] Como guías tratamos de encontrar lo que nos une y lo que tenemos en común a pesar de las diferencias (G4) ${ }^{[19]}$.

El hablar de valores también representa algo positivo para los guías, constantemente están haciendo amigos, siendo solidarios, ayudando a los turistas, facilitando información y en otras siendo ejemplo para los estudiantes del colegio y para otras personas de la comunidad que sí ven este trabajo como algo bueno, contextualiza uno de los guías. 
"Los estudiantes que llegan cada semana a hacer prácticas de interpretación dejan de lado la vergüenza, son más arriesgados, hay un amor propio hacia su trabajo y al lugar donde han nacido, y sobre todo practican la empatía con las diversas personalidades que traen los turistas" (G3) ${ }^{[20]}$.

"Los beneficios no sólo son para el área protegida y los que trabajamos aquí, también son para la comunidad que tiene pequeños negocios, nos preguntan de lugares donde comer o donde alojarse y nosotros le damos esa información" (G4) ${ }^{[21]}$.

$\mathrm{Y}$, finalmente ven este intercambio de conocimientos, como un complemento a la educación formal que se imparte en las escuelas y colegios. Reconocen que ambos son necesarios para mejorar la calidad de la educación local, "no me gustaría que mi hijo sepa muchas cosas modernas y que no conozca nada del campo, ojalá sea experto en las dos cosas" (G6) ${ }^{[22]}$.

\subsection{La educación local: los estudiantes del colegio san lorenzo y la relación escuela-guias nativos}

En el espacio comunitario, adyacente al área protegida donde laboran los guías nativos de Pacoche, se encuentra el Colegio Técnico San Lorenzo, "en sus inicios llevó el nombre de Colegio Municipal San Lorenzo, [...] el cual abrió sus puertas en el año 2002”. (REYES, 2014, p. 29)

Este contexto, funciona a manera de complemento en una zona rural, donde este es la única institución educativa en la Parroquia, que acoge a la población estudiantil, que cursa una formación de segundo nivel (bachillerato) en la zona. Esta conexión entre el colegio y los guías es, considerada uno de los primeros acercamientos comunitarios entre un ente social y otro educativo; así lo ratifica uno de los guías, quien además señala que es una oportunidad para ambos sectores, estima que más que ayudar a los estudiantes a obtener un conocimiento más profundo sobre flora y fauna, son ellos los propios guías, quienes sienten que son parte importante y visible en la formación de los estudiantes.

Una de las formas en las cuales se ha expresado y reproducido la exclusión de pueblos, comunidades e individuos indígenas y afrodescendientes en los procesos de construcción de los Estados y sociedades nacionales en América Latina, ha sido la “invisibilización” (MATO, 2008, p. 29).

"Hemos visto que hay un interés por conocer y replicar lo que aprenden, al principio pensábamos que como eran jóvenes no les iba a interesar el trabajo en medio de la naturaleza, pero nos han demostrado lo contrario" (G3). ${ }^{[23]}$

Estas clases se llevan a efecto cada día domingo, de 8:00 a 12:00, durante dos meses del ciclo escolar. Los estudiantes, previo a esto, reciben formación teórica en las instalaciones del Colegio. Algunas prácticas se dan en el Sendero del Mono y otras en la Playa de San Lorenzo, sin duda a decir por los estudiantes se sienten muy motivados cuando asisten al sendero.

Ese interés de participar aun cuando asisten los días domingo, es una de las satisfacciones de las que hablan tanto el maestro encargado de la asignatura como los guías locales, "en la comunidad, ese día de la semana es casi sagrado para las personas, aprovechan para descansar y si son jóvenes prefieren hacer otras cosas menos estudiar, sin embargo la presencia en Pacoche es asidua y puntual" (M1) ${ }^{[24]}$.

Se ha podido notar que, los estudiantes se han sentido motivados no solo por cumplir, sino por participar y compartir experiencias dentro de la clase. En algunos momentos se intercambiaban roles (guías-visitantesprofesor-estudiante), si alguien estaba hablando y se le escapaba un dato que consideraba importante, alguno de ellos tomaba la palabra y lo compartía. El interés, además se ha orientado en aprender nombres científicos de las especies de flora y fauna del lugar.

El guía los ha invitado a observar, y en ocasiones a tener contacto con especies de flora que han caído de los árboles; perciben sus olores, escuchan y diferencian con atención el ruido como medio de comunicación 
entre los animales, intercambian ideas y aprenden relacionando lo que tienen al momento, con lo que saben o con lo que han aprendido desde sus familias, todo tiene una razón de ser para ellos.

Otro de los guías destaca que,

en medio del intercambio de conocimientos se hace evidente el progreso de los estudiantes con sus competencias actitudinales y aptitudinales, pierden el miedo a hablar en público o con gente que no conocen, escuchan cuando alguien está hablando, trabajan en equipo, no sólo entre ellos, también con nosotros (G6) ${ }^{[25]}$.

Recalcan finalmente, la importancia que tienen las familias de los estudiantes en la construcción de un nuevo conocimiento, asociando lo local con lo universal:

siempre se dice que hay que valorar lo nuestro, pero en nuestras casas no se hace nada para valorar, nos gusta lo que viene de afuera y a veces les decimos a los hijos que tienen que irse a estudiar a otro lado, si quieren progresar. Aquí no hay mucho futuro (G6) ${ }^{[26]}$.

\subsection{Clase en refugio de vida silvestre marino costero de Pacoche}

En el trabajo de campo, realizado en el área Protegida de Pacoche durante el año 2015, se pudo presenciar una clase práctica de la asignatura "Guía de Grupos”, de la especialización de Turismo, que se realizó dentro del Refugio de Pacoche.

Durante el ciclo lectivo, el maestro a cargo de la asignatura convoca cada domingo a los estudiantes a realizar una clase de campo, con el fin de recrear el espacio profesional al cual los estudiantes se enfrentarán en su vida profesional.

Acorde a los comentarios del maestro, la actividad se planifica en dos sesiones con el propósito de aprovechar dos fuentes propias de conocimiento: guías nativos y estudiantes.

En la primera sesión, se enfoca en el aprendizaje experimental facilitado por los guías nativos, los estudiantes reciben una formación enfocada en enseñar técnicas de guiar e interpretación ambiental, en varios transeptos realizan preguntas y dan aportaciones propias tomadas de sus experiencias comunitarias, que en ocasiones provienen de un conocimiento proporcionado por sus familiares. El aula de clases es el medio natural del área protegida.

En la segunda fase, los estudiantes ponen en práctica lo aprendido de la mano de los guías, intercambian roles y hacen una interpretación guiada de la zona. Los demás estudiantes hacen preguntas y simulan un ejercicio de guianza; el maestro hace observaciones, toma notas y en determinados momentos, solo cuando es necesario, interviene para reforzar algún tema relevante y al finalizar el recorrido realiza una evaluación grupal.

El rol del guía nativo es de observador, y al igual que el maestro interviene solo si es necesario corregir o reforzar algún conocimiento propio. Vale recalcar como dato particular que el maestro de esta clase, previamente ha sido un guía nativo del área protegida, lo cual enriquece la práctica, poniendo en juego dos visiones distintas de lo que se enseña y se aprende.

Una vez finalizado el recorrido los estudiantes y el maestro, muestran cierta libertad al expresarse, muy diferente a la que se genera dentro del espacio institucional. Ambas partes consideran que este tipo de clases son fundamentales para enriquecer sus conocimientos y que es una manera flexible para aprender.

Es de mencionar que, durante el ejercicio los estudiantes hacen uso del conocimiento adquirido en el colegio, relacionándolo con la mayoría de las asignaturas que propone el currículo. Llama la atención, como en la práctica se presentan un sinnúmero de aprendizajes que pasan desapercibidos ante las miradas de estudiantes y maestros, ya que su punto de enfoque está centrado en la guianza de grupos y en la interpretación ambiental. 
Ratificando este conocimiento imperceptible se puede resaltar por ejemplo, cómo los estudiantes al observar las manadas de monos aulladores dentro de Pacoche refuerzan criterios aprendidos en clase, sobre anatomía, las diferencias de género de las especies, sus formas de organización social, el sistema de reproducción o tiempos de vida; siendo capaces de complementar la experiencia que han tenido en aula con algunas asignaturas como biología o anatomía, recibidas en los cursos previos al bachillerato.

Lo mismo ocurre con algunas especies de flora como la caña guadua; en la práctica identifican procesos de reproducción, usos en la medicina, mitos y tradiciones relacionados a la especie. Es evidente que este tipo de conocimiento adquirido inconscientemente, y que seguramente lo saben por sus familias y por el entorno en el que han crecido, no es puesto en valor como riqueza académica de la cual se puede sacar provecho en su formación colegial. Sin duda la separación que ha existido entre lo aprendido tradicionalmente en la comunidad, con el conocimiento universal que propone el sector educativo, es uno de los grandes desafíos sí se quiere trabajar en un modelo de educación intercultural pleno.

\section{DISCUSIÓN Y CONCLUSIONES}

Uno de los elementos que destacan producto de esta investigación, además del reflejo de las relaciones asimétricas entre visitante-visitado, es la separación que se hace entre la legitimización del saber propio con la actividad turística, se destaca la inminente necesidad de encontrar otros elementos para fortalecer el turismo, dejando a un lado la sabiduría y el conocimiento local, como una fuente de enriquecimiento para turistas y anfitriones.

A pesar del intercambio que se propicia, tanto para los guías como para los estudiantes y maestros, hace falta apuntar hacia un trabajo reflexivo que se construya desde el colegio o en su sentido más amplio desde la educación, valorando la escuela y el turismo en un marco de trascendencia geográfica hacia el plano de las relaciones humanas. Pensar el turismo desde la mirada intercultural, podría coadyuvar en obtener relaciones rítmicas que nos hagan pensar que, la actividad turística puede ser intercultural si se la plantea desde los márgenes del respeto, y sin barreras imaginarias que deslegitimizan los deberes y derechos de turistas, pero sobre todo de los entes comunitarios.

Las prácticas hegemónicas y repetitivas de los visitados, han llevado a pensar erróneamente a los guías que, es así como se debe concebir el turismo, como un espectáculo que se debe montar para el turista, dejando de lado su parte más esencial, la cual radica en la cotidianidad de sus vidas y de las formas que estas conllevan. Ninguna de las partes debería meterse en un papel disfrazado ni para disfrutar ni para satisfacer.

Otra de las conclusiones, conlleva a considerar que la propuesta educativa actual, es difusa y no encaja en su totalidad con el estilo y compás de vida comunitario en San Lorenzo, puesto que, al momento de buscar las salidas profesionales de la carrera, se plantea limitadamente la opción laboral de guías del área protegida. Para ello es válido abrir el debate y construir un currículo ajustable a la sociedad parroquial, que valore el conocimiento universal que proporcionan las ciencias de manera indiscutible, pero que también se conecte con en el recreativo local, y en donde haya cabida para nuevos actores en la dinámica formativa. De otra manera la educación seguirá siendo la consecuencia de una realidad ajena, en la que los estudiantes se sentirán extraños, sin cabida y sin futuro.

De esta premisa anterior se puede concluir que, la visión turística comunitaria es limitada, no sólo por el panorama que avizoran sus habitantes, sino también porque la perspectiva del turista sigue buscando la práctica de un ejercicio desigual, de vulnerabilidad hacia los visitados, en donde se extraen folclórica y prístinamente experiencias prefabricadas por la tradición en su afán de ocio, sin miras a un repensar que genere nuevas alternativas para aquellos que visitan y son visitados. 


\section{REFERENCIAS}

AGUADO, T. La educación intercultural en la práctica escolar: investigación en el ámbito español. España, p. 43. 2005.

ASAMBLEA CONSTITUYENTE. Constitución de la República del Ecuador. Ecuador. 2008. [En línea]. Disponible en: www.asambleanacional.gob.ec/documentos/constitucion_de_bolsillo.Pdf. Acceso en: 15 sep. 2018.

BOISSEVAIN, J. Rituales ocultos. Protegiendo la cultura de la mirada turística. Pasos. Revista de turismo y patrimonio cultural, v. 3, n. 2, p. 217-228. 2005.

CANCLINI, N. Todos tienen cultura: ¿quiénes pueden desarrollarla? In Conferência no Seminário sobre Cultura y Desarrollo. Washington: Banco Interamericano de Desenvolvimento. Feb, 2005.

ECUADOR. Plan nacional del buen vivir. Obtenido de Constituyendo un Estado Plurinacional e Intercultural. p. 7. [En línea]. Disponible en: https://issuu.com/publisenplades/docs/pnbv_2009-2013. Acceso en: 10 nov. 2016.

KALINSKY, B.; PÉREZ, G. De aquí y de allá: la ambigüedad etnográfica de la otredad. Revista Iztapalapa, v. 30, p. 51-65. 1993.

MALIK, B. Intervenciones para la adquisición de competencias interculturales. E. Repetto (Direct.) Modelos de orientación e intervención psicopedagógica. v. 2, p. 424-452. España. 2003.

MATO, D. Diversidad cultural e interculturalidad en educación superior: experiencias en América Latina. Organización de las Naciones Unidas para la Educación, la Ciencia y la Cultura, Instituto Internacional de la Unesco para la Educación Superior en América Latina y el Caribe, 2008.

MINISTERIO DE EDUCACIÓN DEL ECUADOR. Marco Legal Educativo: Constitución de la República, Ley Orgánica de Educación Intercultural, Reglamento General. Ecuador. 2013. [En línea]. Disponible en: http:// educacion.gob.ec/wp-content/uploads/downloads/2013/01/marco_legal_educativo_2012.pdf. Acceso en: 30 sep. 2018.

MINISTERIO DE EDUCACIÓN DEL ECUADOR. Modelos del Sistema de Educación Intercultural Bilingüe (Moseib). Ecuador. 2013. [En línea]. Disponible en: https://educacion.gob.ec/wp-content/uploads/ downloads/2014/03/MOSEIB.pdf. Acceso en: 30 sep. 2018.

MINISTERIO DE TURISMO. Agencia Andes Mintur. [En línea]. Disponible en: http://www.turismo.gob.ec/ ecuador-espera-recibir-mas-de-16-millones-de-turistas-extranjeros-en-el-2015/ . Acceso en: 10 nov. 2016.

ORGANIZACIÓN MUNDIAL DEL TURISMO. Sustainable Development of Tourism. [En línea]. Disponible en: http://sdt.unwto.org/es/content/definicion. Acceso en: 10 nov. 2016.

PACOCHE, M. C. de; AMBIENTAL, U. P. E. I. Plan de manejo del refugio de vida silvestre y. p. 30 . [En línea]. Disponible en: http://simce.ambiente.gob.ec/sites/default/files/documentos/belen/a.\%20Plan\%20de \%20Manejo\%20Pacoche-\%20Cartograf\%C3\%ADa.pdf. Acceso en: 5 oct. 2018.

REYES, D. Problemas de aprendizajes académicos en adolescentes de 11 a 15 años de la unidad educativa" San Lorenzo" Parroquia rural de la ciudad de Manta, durante el periodo enero a junio 2013 (Doctoral dissertation). 2014.

RUHLY, S. Orientations to intercultural communication. Science Research Associates. 1976.

SALAZAR, B. Antropología del turismo en países en desarrollo: análisis crítico de las culturas, poderes e identidades generados por el turismo. Tabula rasa, 2006, n. 5, p. 99-128.

WALSH, C. Interculturalidad, E., \& Sociedad, L. Coloniales de nuestra época. Quito: Universidad Andina Simón Bolívar/Abya-Yala, 2009.

ZAPATA, C. Las Ficciones del Turismo. [En línea]. Disponible en: http://www.elmostrador.cl/ opinion/2015/01/24/la-ficciones-del-etnoturismo/ . Acceso en: 10 nov. 2016. 


\section{Notas}

[1] Trabajo de Fin de Máster

[2] Ministerio de Turismo - Ecuador

[3] Provincia de la Costa Ecuatoriana

[4] Zapata, C. (2013). Las Ficciones del Turismo.

[5]Plan Nacional del Buen Vivir. Ecuador

[6] Organización Mundial del Turismo

[7] Autora. (2015). [Entrevista con Guía 1 nativo del área protegida RFVSMC Pacoche, cantón Manta, parroquia San Lorenzo]

[8] Triturar algo, por ejemplo, machacar algún alimento.

[9]Pararse recto, sin encorvar la columna.

[10] Ministerio de Ambiente del Ecuador.

[11]Gobierno Autónomo Descentralizado.

[12] Plan de Manejo del Refugio de Vida Silvestre y Marino Costero de Pacoche. Ver http://simce.ambiente.gob.ec/sites/default/ files/documentos/belen/a.\%20Plan\%20de\%20Manejo\%20Pacoche-\%20Cartograf\%C3\%ADa.pdf.

[13] Autora. (2015). [Entrevista con Guía 2 del área protegida RFVSMC Pacoche, cantón Manta, parroquia San Lorenzo]

[14] Autora. (2015). [Entrevista con Guía 5 del área protegida RFVSMC Pacoche, cantón Manta, parroquia San Lorenzo]

[15] Autora. (2015). [Entrevista con Guía 6 del área protegida RFVSMC Pacoche, cantón Manta, parroquia San Lorenzo]

[16] Autora. (2015). [Entrevista con G5 del área protegida RFVSMC Pacoche, cantón Manta, parroquia San Lorenzo]

[17] Autora. (2015). [Entrevista con G2 del área protegida RFVSMC Pacoche, cantón Manta, parroquia San Lorenzo]

[18] Autora. [Entrevista con Guía 2 nativo del área protegida RFVSMC Pacoche, cantón Manta, parroquia San Lorenzo]

[19] Autora. (2015). [Entrevista con Guía 4 del área protegida RFVSMC Pacoche, cantón Manta, parroquia San Lorenzo]

[20] Autora. (2015). [Entrevista con Guía 3 del área protegida RFVSMC Pacoche, cantón Manta, parroquia San Lorenzo]

[21] Autora. (2015). [Entrevista con Guía 4 del área protegida RFVSMC Pacoche, cantón Manta, parroquia San Lorenzo]

[22] Autora. (2015). [Entrevista con Guía 6 del área protegida RFVSMC Pacoche, cantón Manta, parroquia San Lorenzo]

[23] Autora. (2015). [Entrevista con Guía 3 del área protegida RFVSMC Pacoche, cantón Manta, parroquia San Lorenzo]

[24] Autora. (2015). [Entrevista con Maestro 1, Colegio San Lorenzo, cantón Manta, parroquia San Lorenzo]

[25] Autora. (2015). [Entrevista con Guía 6 del área protegida RFVSMC Pacoche, cantón Manta, parroquia San Lorenzo]

[26] Autora. (2015). [Entrevista con Guía 6 del área protegida RFVSMC Pacoche, cantón Manta, parroquia San Lorenzo]

\section{BY}

